\title{
HUBUNGAN PENGGUNAAN RANSEL DENGAN NYERI PUNGGUNG DAN KELAINAN BENTUK TULANG BELAKANG PADA SISWA DI SMP NEGERI 2 TOMBATU
}

\author{
${ }^{1}$ Stefany V. Dumondor \\ ${ }^{2}$ Engeline Angliadi \\ ${ }^{2}$ Lidwina Sengkey \\ ${ }^{1}$ Kandidat Skripsi Fakultas Kedokeran Universitas Sam Ratulangi Manado \\ ${ }^{2}$ Program Studi Kedokteran Fidsik dan Rehabilitasi \\ Email: sdumondor11_182@yahoo.co.id
}

\begin{abstract}
Abstrak: Tas jenis ransel sangat diminati oleh anak sekolah.Banyaknya peminat yang menggunakan ransel disebabkan karena tas ini lebih praktis dan memiliki daya tampung yang lebih besar. Meskipun banyak diminati, penggunaan ransel yang tidak sesuai dari segi desain, berat beban, maupun cara pemakaiannya memiliki dampak negatif yang cukup besar bagi anak sekolah karena dapat meningkatkan stres pada struktur tulang belakang anak yang sedang dalam masa pertumbuhan. Penggunaan ransel yang tidak sesuai dapat menyebabkan nyeri punggung, perubahan postur tubuh dan gaya berjalan dan jika dilakuan terus menerus dapat mengakibatkan perubahan yang bersifat irreversible karena ligamen dan tulang belakang terus mengalami proses degeneratif sejalan dengan usia. Penelitian ini bertujuan untuk mengetahui hubungan penggunaan ransel dengan nyeri punggung dan kelainan bentuk tulang belakang pada siswa yang dilakukan di SMP Negeri 2 Tombatu. Penelitian ini bersifat obsevasional analitik dengan pendekatan cross sectional, yaitu dengan melakukan pengamatan langsung kepada subjek penelitian dengan penyebaran kuesioner dan pemeriksaan tulang belakang dengan teknik adam forward bending test. Hasil penelitian dari 30 sampel, didapati 25 orang pernah merasakan nyeri di daerah leher, bahu, punggung bagian atas, maupun punggung bagian bawah. Berdasarkan pemeriksaan tulang belakang, dari 30 sampel 12 orang memiliki tulang belakang normal, sedangkan 18 orang didapati memiliki kelainan tulang belakang yaitu 6 orang dengan skoliosis, 10 orang kifosis dan 2 orang lordosis. Analisis statistik yang digunakan adalah Chi-Square karena salah satu variabel yang diuji berskala nominal dan uji Spearman karena kedua variabel yang diuji berskala ordinal dengan menggunakan $\alpha=5 \%$ atau 0,05 .
\end{abstract}

Kata Kunci: ransel, nyeri punggung, kelainan bentuk tulang belakang, anak sekolah

Tas merupakan salah satu alat bantu dalam aktivitas carrying yang merupakan jenis aktivitas Manual Material Handling. Tas digunakan pelajar untuk membawa buku, alat tulis, maupun keperluan sekolah lainnya ke dan dari sekolah. Di Amerika Serikat sekitar 4 juta anak menggunakan ransel untuk membawa barang-barang kebutuhan mereka. ${ }^{1}$ Lebih dari $90 \%$ pelajar di Negara berkembang dilaporkan menggunakan ransel. ${ }^{2}$ Meskipun banyak diminati, ternyata ransel dapat menyebabkan masalah kesehatan apabila penggunaannya tidak tepat. ${ }^{1}$

Kebanyakan pelajar membawa ransel melebihi berat yang direkomendasikan. ${ }^{3}$ Berat ransel yang disarankan adalah 10\% sampai $15 \%$ dari berat badan anak. ${ }^{1,2,4}$ Anak yang membawa ransel melebihi berat yang direkomendasikan mempunyai resiko lebih tinggi untuk menderita nyeri punggung dan terjadinya kelainan tulang belakang. ${ }^{4}$

Penggunaan ransel yang berat secara 
berulang diyakini meningkatkan stress pada struktur tulang belakang (diskus intervertebra, ligamen, dll) anak dan remaja yang sedang dalam masa pertumbuhan (rapid growth). ${ }^{5}$ Semakin berat beban ransel menyebabkan terjadinya penekanan pada diskus yang mempunyai fungsi sebagai bantalan antar tulang pada tulang belakang. Penggunaan ransel dengan beban yang berat juga berhubungan dengan peningkatan kelengkungan tulang belakang bagian bawah. ${ }^{6}$ Kelainan pada tulang belakang yang sering terjadi pada anak usia SD dan SMP adalah skoliosis, lordosis dan kifosis yang diakibatkan oleh kebiasan membawa tas yang tidak tepat. ${ }^{1}$

Nyeri punggung pada anak sekolah dapat disebabkan oleh beberapa faktor, antara lain faktor aktivitas fisik, nutrisi, psikologis dan gangguan patologis. Tingkat aktivitas fisik anak sering dihubungkan dengan kejadian nyeri punggung.Anak dengan aktifitas fisik berat atau rendah memiliki resiko nyeri punggung lebih besar.Selain itu, status nutrisi berlebih atau obesitas juga mempengaruhi nyeri punggung.Hal ini disebabkan karena adanya peningkatan beban yang harus ditopang oleh tulang belakang.Faktor psikologis, seperti kecemasan, stress, dan depresi dapat menurunkaan ambang batas nyeri sehingga anak mudah mengalami nyeri. Sedangkan kondisi patologis, seperti perubahan postur tubuh juga dapat meningkatkan kerentanan anak mengalami nyeri punggung. ${ }^{7}$ Penyebab nyeri punggung lainnya, yaitu penggunaan ransel. ${ }^{8}$ Penggunaan ransel yang tidak sesuai, baik dari segi desain, berat beban, maupun cara penggunaan, dan apabila sering digunakan, dapat mengakibatkan nyeri punggung pada anak sekolah. $^{7}$

Penggunaan ransel yang tidak sesuai memiliki dampak negatif yang cukup besar bagi anak sekolah, antara lain dapat menimbulkan nyeri punggung, perubahan postur tubuh dan gaya berjalan. Jika kebiasaan salah dalam menggunakan ransel terus menerus dilakukan dapat mengkibatkan perubahan yang bersifat irreversible karena ligamen dan tulang- tulang belakang belakang terus mengalami proses degenaratif sejalan dengan usia. ${ }^{7}$

Tujuan dari penelitian ini adalah untuk mengetahui hubungan antara penggunaan ransel dengan nyeri punggung dan kelainan bentuk tulang belakang pada siswa SMP dan angka kejadian nyeri punggung dan kelainan bentuk tulang belakang pada siswa SMP.

\section{METODE PENELITIAN}

Desain penelitian yang digunakan pada penelitian ini adalah observasional analitik dengan pendekatan cross-sectional, yaitu penelitian dilakukan dengan menimbang berat tas, menyebarkan kuesioner untuk menilai nyeri punggung, dan melakukan pemeriksaan tulang belakang dengan Adam forward bending test. Dilakukan pada bulan Oktober-Desember 2014. Sampel penelitiannya adalah seluruh siswa kelas VIII SMP Negeri 2 Tombatu yang menggunakan ransel dan memenuhi kriteria inklusi, yaitu sebanyak 30 orang terdiri dari 14 orang laki-laki dan 16 orang perempuan.

\section{HASIL PENELITIAN DAN BAHASAN}

Berdasarkan pemeriksaan tulang belakang yang dilakukan, dari 30 sampel 12 orang memiliki tulang belakang normal, sedangkan 18 orang didapati memiliki kelainan tulang belakang yang terdiri dari 10 orang laki-laki dan 8 orang perempuan. Hasil penelitian mengenai karakteristik responden terhadap kelainan bentuk tulang belakang di atas didapati IMT memiliki hubungan dengan kelainan bentuk tulang belakang dengan nilai $\mathrm{P}$ sebesar $0,017(\alpha=$ 5\%). Dimana, responden dengan IMT dibawa normal lebih banyak mengalami kelainan bentuk tulang belakang.Hal yang sama juga ditemukan pada penelitiansebelumnya yang dilakukan oleh Hershkovich menemukan adanya hubungan yang besar antara berat badan kurang dengan kelainan bentuk tulang belakang. ${ }^{9}$

Pada analisis mengenai hubungan persentase berat tas berdasarkan berat badan dengan kelainan bentuk tulang diperoleh nilai $\mathrm{p}$ sebesar $0,219(\alpha=5 \%)$ sehingga hipotesis $\mathrm{H}_{1}$ diterima atau tidak 
terdapat hubungan antara persentase berat tas berdasarkan berat badan dengan kelainan bentuk tulang belakang. Pada pengukuran berat tas, didapati persentasi berat tas sekolah berdasarkan berat badan semua responden masih dalam batas normal yang di rekomendasikan oleh American Chiropratic Assosiation yaitu tidak lebih dari 10\%-15\% dari berat badan anak. Anak yang membawa tas ransel melebihi berat yang direkomendasikan mempunyai resiko lebih tinggi untuk menderita nyeri punggung dan terjadinya kelainan tulang belakang. ${ }^{3}$

Dari 30 sampel, didapati hanya 5 orang yang tidak pernah mengeluh nyeri.Sedangkan 25 orang lainya pernah merasakan nyeri di bagian leher, bahu, punggung bagian atas dan punggung bagian bawah. Berdasarkan hasil penelitian karakteristik responden dengan nyeri diperoleh perempuan (46,7\%) lebih banyak mengalami nyeri punggung dari pada lakilaki (36,7\%). Penelitian sebelumnya juga mendapatkan bahwa angka kejadian nyeri punggung pada perempuan lebih tinggi dari pada laki-laki. ${ }^{5}$ Hasil analisis hubungan ransel dengan kelainan bentuk tulang belakang antara variabel persentase berat tas dengan nyeri diperoleh nilai $\mathrm{p}$ sebesar $0,264(\alpha=5 \%)$ sehingga disimpulkan tidak terdapat hubungan antara penggunaan ransel dengan nyeri punggung atau $\mathrm{HO}_{2}$ diterima karena persentasi berat tas terbadap berat badan masih dalam batas yang direkomendasikan. Selain itu, faktor lain yang dapat menyebabkan nyeri punggung pada anak sekolah adalah faktor aktivitas fisik, nutrisi, psikologis dan gangguan patologis.

Tabel 1. Karakteristik Responden berdasarkan Kelainan Tulang Belakang

\begin{tabular}{|c|c|c|c|c|c|c|c|c|c|c|c|c|}
\hline \multirow[b]{3}{*}{ Variabel } & \multirow{3}{*}{ Kategori } & \multicolumn{10}{|c|}{ Kelainan tulang belakang } & \\
\hline & & \multicolumn{2}{|c|}{ Normal } & \multicolumn{2}{|c|}{ Kifosis } & \multicolumn{2}{|c|}{ Lordosis } & \multicolumn{2}{|c|}{ Skoliosis } & \multicolumn{2}{|c|}{ Total } & \\
\hline & & $\mathrm{N}$ & $\%$ & $\mathrm{n}$ & $\%$ & $\mathrm{n}$ & $\%$ & $\mathrm{n}$ & $\%$ & $\mathrm{~N}$ & $\%$ & \\
\hline \multirow{4}{*}{ Umur } & 12 tahun & 3 & 10 & 2 & 6,7 & 0 & 0 & 3 & 10 & 8 & 26,7 & \multirow{5}{*}{$\begin{array}{c}P \text { value } \\
0,588\end{array}$} \\
\hline & 13 tahun & 8 & 26,7 & 4 & 13,3 & 2 & 6,7 & 3 & 10 & 17 & 56,7 & \\
\hline & 14 tahun & 0 & 0 & 4 & 13,3 & 0 & 0 & 0 & 0 & 4 & 13,3 & \\
\hline & 15 tahun & 1 & 3,3 & 0 & 0 & 0 & 0 & 0 & 0 & 1 & 3,3 & \\
\hline \multicolumn{2}{|r|}{ Total } & 12 & 40 & 10 & 33,3 & 2 & 6,7 & 6 & 20 & 30 & 100 & \\
\hline Jenis & Laki-laki & 4 & 13,3 & 7 & 23,3 & 0 & 0 & 3 & 10 & 14 & 46,7 & \multirow{3}{*}{$\begin{array}{c}\text { P value } \\
0,185\end{array}$} \\
\hline \multirow[t]{2}{*}{ kelamin } & Perempuan & 8 & 26,7 & 3 & 10 & 2 & 6,7 & 3 & 10 & 16 & 53,3 & \\
\hline & Total & 12 & 40 & 10 & 33,3 & 2 & 6,7 & 6 & 20 & 30 & 100 & \\
\hline \multirow{4}{*}{$\begin{array}{l}\text { Berat } \\
\text { badan }\end{array}$} & $<30 \mathrm{~kg}$ & 0 & 0 & 1 & 3,3 & 0 & 0 & 1 & 3,3 & 2 & 6,7 & \multirow{5}{*}{$\begin{array}{c}P \text { value } \\
0,060\end{array}$} \\
\hline & $31-40 \mathrm{~kg}$ & 4 & 13,3 & 3 & 10 & 0 & 0 & 4 & 13,3 & 11 & 36,7 & \\
\hline & $41-50 \mathrm{~kg}$ & 5 & 16,7 & 5 & 16,7 & 2 & 6,7 & 1 & 3,3 & 13 & 43,3 & \\
\hline & $>51 \mathrm{~kg}$ & 3 & 10 & 1 & 3,3 & 0 & 0 & 0 & 0 & 4 & 13,3 & \\
\hline \multicolumn{2}{|r|}{ Total } & 12 & 40 & 10 & 33,3 & 2 & 6,7 & 6 & 20 & 30 & 100 & \\
\hline \multirow{3}{*}{$\begin{array}{l}\text { Tinggi } \\
\text { badan }\end{array}$} & $<140$ & 1 & 3,3 & 1 & 3,3 & 0 & 0 & 0 & 0 & 2 & 6,7 & \multirow{4}{*}{$\begin{array}{c}\text { P value } \\
0,860\end{array}$} \\
\hline & $141-150$ & 7 & 23,3 & 3 & 10 & 2 & 6,7 & 4 & 13,3 & 16 & 53,3 & \\
\hline & 151-160 & 4 & 13,3 & 6 & 20 & 0 & 0 & 2 & 6,7 & 12 & 40 & \\
\hline & Total & 12 & 40 & 10 & 33,3 & 2 & 6,7 & 6 & 20 & 30 & 100 & \\
\hline \multirow{4}{*}{ IMT } & $<18,5$ & 4 & 13,3 & 5 & 16,7 & 0 & 0 & 6 & 20 & 15 & 50 & \multirow{5}{*}{$\begin{array}{c}\text { P value } \\
0,017\end{array}$} \\
\hline & $18,5-22,9$ & 5 & 16,7 & 5 & 16,7 & 2 & 6,7 & 0 & 0 & 12 & 40 & \\
\hline & $23-24,9$ & 2 & 6,7 & 0 & 0 & 0 & 0 & 0 & 0 & 2 & 6,7 & \\
\hline & 25-29,9 & 1 & 3,3 & 0 & 0 & 0 & 0 & 0 & 0 & 1 & 3,3 & \\
\hline \multirow{4}{*}{$\begin{array}{l}\text { \%Berat } \\
\text { Tas/BB }\end{array}$} & Total & 12 & 40 & 10 & 33,3 & 2 & 6,7 & 6 & 20 & 30 & 100 & \\
\hline & $<5 \%$ & 10 & 33,3 & 8 & 26,7 & 2 & 6,7 & 3 & 10 & 23 & 76,7 & \multirow{4}{*}{$\begin{array}{c}\text { P value } \\
0,219\end{array}$} \\
\hline & $5-10 \%$ & 2 & 6,7 & 2 & 6,7 & 0 & 0 & 2 & 6,7 & 6 & 20 & \\
\hline & $10-15 \%$ & 0 & 0 & 0 & 0 & 0 & 0 & 1 & 3,3 & 1 & 3,3 & \\
\hline \multirow{3}{*}{ Nyeri } & Total & 12 & 40 & 10 & 33,3 & 2 & 6,7 & 6 & 20 & 30 & 100 & \\
\hline & $\mathrm{Ya}$ & 11 & 36,7 & 8 & 26,7 & 1 & 3,3 & 5 & 16,7 & 25 & 83,3 & \multirow{3}{*}{$\begin{array}{c}\text { P value } \\
0,516\end{array}$} \\
\hline & Tidak & 1 & 3,3 & 2 & 6,7 & 1 & 3,3 & 1 & 3,3 & 5 & 16,7 & \\
\hline & Total & 12 & 40 & 10 & 33,3 & 2 & 6,7 & 6 & 20 & 30 & 100 & \\
\hline
\end{tabular}


Dumondor, Angliady, Sengkey: Hubungan penggunaan ransel...

Tabel 2. Karakteristik Responden terhadap Nyeri

\begin{tabular}{|c|c|c|c|c|c|c|c|c|}
\hline \multirow[b]{3}{*}{ Variabel } & \multirow{3}{*}{ Kategori } & \multicolumn{6}{|c|}{ Nyeri } & \\
\hline & & \multicolumn{2}{|c|}{ Ya } & \multicolumn{2}{|c|}{ Tidak } & \multicolumn{2}{|c|}{ Total } & \multirow{6}{*}{$\begin{array}{c}P \text { value } \\
0,648\end{array}$} \\
\hline & & $\mathrm{n}$ & $\%$ & $\mathrm{n}$ & $\%$ & $\mathrm{n}$ & $\%$ & \\
\hline \multirow{4}{*}{ Umur } & 12 tahun & 8 & 26,7 & 0 & 0 & 8 & 36,7 & \\
\hline & 13 tahun & 12 & 40 & 5 & 16,7 & 17 & 56,7 & \\
\hline & 14 tahun & 4 & 13,3 & 0 & 0 & 4 & 13,3 & \\
\hline & 15 tahun & 1 & 3,3 & 0 & 0 & 2 & 3,3 & \\
\hline \multicolumn{2}{|c|}{ Total } & 25 & 83,3 & 5 & 16,7 & 30 & 100 & \multirow{4}{*}{$\begin{array}{c}\text { P value } \\
0,513\end{array}$} \\
\hline \multirow{2}{*}{ Jenis Kelamin } & Laki-laki & 11 & 36,7 & 3 & 10 & 14 & 46,7 & \\
\hline & Perempuan & 14 & 46,7 & 2 & 6,7 & 16 & 53,3 & \\
\hline \multicolumn{2}{|c|}{ Total } & 25 & 83,3 & 5 & 16,7 & 30 & 100 & \\
\hline \multirow{4}{*}{ Berat Badan } & $<30 \mathrm{~kg}$ & 0 & 0 & 2 & 6,7 & 2 & 6,7 & \multirow{5}{*}{$\begin{array}{c}P \text { value } \\
0,727\end{array}$} \\
\hline & $31-40 \mathrm{~kg}$ & 11 & 36,7 & 0 & 0 & 11 & 36,7 & \\
\hline & $41-50 \mathrm{~kg}$ & 11 & 36,6 & 2 & 6,7 & 13 & 43,3 & \\
\hline & $51 \mathrm{~kg}$ & 3 & 10 & 1 & 3,3 & 4 & 13,3 & \\
\hline \multicolumn{2}{|c|}{ Total } & 25 & 83,3 & 5 & 16,7 & 30 & 100 & \\
\hline \multirow{3}{*}{ Tinggi Badan } & $<140 \mathrm{~m}$ & 2 & 6,7 & 0 & 0 & 2 & 6,7 & \multirow{4}{*}{$\begin{array}{c}\text { Pvalue } \\
0,499\end{array}$} \\
\hline & $141-150 \mathrm{~m}$ & 12 & 40 & 4 & 13,3 & 16 & 53,3 & \\
\hline & $151-160 \mathrm{~m}$ & 11 & 36,7 & 1 & 3,3 & 12 & 40 & \\
\hline \multicolumn{2}{|c|}{ Total } & 25 & 83,3 & 5 & 16,7 & 30 & 100 & \\
\hline \multirow{4}{*}{ IMT } & $<18,5$ & 13 & 43,4 & 2 & 6,7 & 15 & 50 & \multirow{5}{*}{$\begin{array}{c}\text { P value } \\
0,546\end{array}$} \\
\hline & $18,5-22,9$ & 10 & 33,3 & 2 & 6,7 & 12 & 40 & \\
\hline & $23-24,9$ & 1 & 3,3 & 1 & 3,3 & 2 & 6,7 & \\
\hline & $25-29,9$ & 1 & 3,3 & 0 & 0 & 1 & 3,3 & \\
\hline \multicolumn{2}{|c|}{ Total } & 25 & 83,3 & 5 & 16,7 & 30 & 100 & \\
\hline \multirow{3}{*}{ \%Berat Tas/BB } & $<5 \%$ & 20 & 66,7 & 3 & 10 & 23 & 76,7 & \multirow{4}{*}{$\begin{array}{r}\mathrm{P} \text { value } \\
0,264\end{array}$} \\
\hline & $5-10 \%$ & 5 & 16,7 & 1 & 3,3 & 6 & 20 & \\
\hline & $10-15 \%$ & 0 & 0 & 1 & 3,3 & 1 & 3,3 & \\
\hline \multicolumn{2}{|c|}{ Total } & 25 & 83,3 & 5 & 16,7 & 30 & 100 & \\
\hline
\end{tabular}

Tingkat aktivitas fisik anak sering dihubungkan dengan kejadian nyeri punggung.Anak dengan aktivitas fisik berat atau rendah memiliki resiko nyeri punggung lebih besar. Selain itu, status nutrisi berlebih atau obesitas juga mempengaruhi nyeri punggung. Hal ini disebabkan karena adanya peningkatan beban yang harus ditopang oleh tulang belakang. Faktor psikologis, seperti kecemasan, stress, dan depresi dapat menurunkan ambang batas nyeri sehingga anak mudah mengalami nyeri. Sedangkan kondisi patologis, seperti perubahan postur tubuh juga dapat meningkatkan kerentanan anak mengalami nyeri punggung. ${ }^{11}$

\section{SIMPULAN DAN SARAN}

Dari hasil penelitian disimpulkan tidak terdapat hubungan antara ransel dan nyeri punggung dengan nilai p sebesar $=0,264$. Juga tidak terdapat hubungan antara ransel denan kelainan bentuk tulang belakang dengan nilai p sebesar 0,219.

Dari hasil penelitian, dapat disarankan beberapa hal :

1. Perlunya memperhatikan faktor-faktor lain yang dapat memperngaruhi subjek penelitian, seperti aktivitas fisik lain.

2. Perlunya jumlah sampel yang lebih besar sehingga hasilnya lebih objektif.

\section{DAFTAR PUSTAKA}

1. Wulandari D. Perbedaan derajat kifosis berdasarkan tas ransel, umur dan jenis kelamin pada anak SMPN 191 Jakarta barat. 2013. Available from:

http://digilib.esaunggul.ac.id/publi c/UEU-Undergraduate-870- 
bab\%20I.pdf

2. Chow DHK, Ou ZY, Wang XG, and Lai A. Short-term effects of backpack load placement on spine deformation and repositioning error in schoolchildren. Ergonomics. 2010; 53:56-64. Available from:

http://dx.doi.org/10.1080/0014013 0903389050

3. Rodriguez-Oviedo P, Ruano-Ravina A, Perez-Rios M, et al. School children's backpacks, back pain and back pathologies. Arch Dis Chil. Aug 2012;97(8):730-732.

4. Brackley HM, Stevenson JM. Are children's backpack weight limits enough? A critical review of the relevant literature. Spine (Phila $\mathrm{Pa}$ 1976). Oct 1 2004;29(19):21842190.

5. Korovessis P, Koureas G, Papazisis Z. Correlation between backpack weight and way of carrying, sagittal and frontal spinal curvatures, athletic activity, and dorsal and low back pain in schoolchildren and adolescents. $J$ Spinal Disord Tech. Feb 2004;17(1):33-40.

6. Warner J. Heavy backpack strain kids' spines [internet]. 2010. Available from:

http://www.webmd.com/children/ news/20100203/heavy-backpacksstrain-kids-spines
7. Sya'bani PD. Hubungan tingkat pengetahuan tentang backpack safety terhadap keluhan nyeri punggung pada siswa kelas 5 di kelurahan Tegal panjang Garut. 2012. Available from: http://www.google.co.id/url?sa=t\& $\mathrm{rct}=\mathrm{j} \& \mathrm{q}=$ \&esrc $=\mathrm{s} \&$ source $=$ web $\& \mathrm{c}$ $\mathrm{d}=1 \&$ ved $=0$ CCIQFjAA\&url=http \%3A\%2F\%2Flib.ui.ac.id\%2Ffile \%3Ffile\%3Ddigital\%2F20312684 -S\%252043158-

Hubungan\%2520tingkat-

full\%2520text.pdf\&ei=L7QhVLn FOcKgugSZj4CgAQ\&usg=AFQj CNEwPskRs5ZIy4oXAA95K5Mx 5BDiRA\&bvm=bv.75775273,d.c2 E\&cad=rja

8. Valerie R, Carita D, ConneMara. An educational exercise on backpacks for school children: including children, faculty and parents. $2008 . \quad$ Available from:http://www.childergo.com/ba ckpackergonomics.pdf

9. Hershkovich O, Friedlander A, Gordon B, et al. Association between body mass index, body height, and the prevalence of spinal deformities. The Spine Journal. 2014;14;1581-1587. Avaiable from: http://lib.ajaums.ac.ir/booklist/1s2.0-S152994301301574Xmain.pdf. 